\title{
Verification of precipitation forecasts by the DWD limited area model LME over Cyprus
}

\author{
K. Savvidou ${ }^{1}$, S. C. Michaelides ${ }^{1}$, A. Orphanou ${ }^{1}$, P. Constantinides ${ }^{1}$, J.-P. Schulz ${ }^{2}$, U. Voigt ${ }^{2}$, and M. Savvides ${ }^{3}$ \\ ${ }^{1}$ Meteorological Service, Nicosia, Cyprus \\ ${ }^{2}$ Deutscher Wetterdienst, Offenbach am Main, Germany \\ ${ }^{3}$ Department of Lands and Surveys, Nicosia, Cyprus
}

Received: 7 July 2006 - Revised: 2 January 2007 - Accepted: 3 January 2007 - Published: 26 April 2007

\begin{abstract}
A comparison is made between the precipitation forecasts by the non-hydrostatic limited area model LME of the German Weather Service (DWD) and observations from a network of rain gauges in Cyprus. This is a first attempt to carry out a preliminary verification and evaluation of the LME precipitation forecasts over the area of Cyprus.

For the verification, model forecasts and observations were used covering an eleven month period, from 1/2/2005 till 31/12/2005. The observations were made by three Automatic Weather Observing Systems (AWOS) located at Larnaka and Paphos airports and at Athalassa synoptic station, as well as at 6, 6 and 8 rain gauges within a radius of about $30 \mathrm{~km}$ around these stations, respectively. The observations were compared with the model outputs, separately for each of the three forecast days.

The "probability of detection" (POD) of a precipitation event and the "false alarm rate" (FAR) were calculated. From the selected cases of the forecast precipitation events, the average forecast precipitation amounts in the area around the three stations were compared with the measured ones.

An attempt was also made to evaluate the model's skill in predicting the spatial distribution of precipitation and, in this respect, the geographical position of the maximum forecast precipitation amount was contrasted to the position of the corresponding observed maximum. Maps with monthly precipitation totals observed by a local network of 150 rain gauges were compared with the corresponding forecast precipitation maps.
\end{abstract}

Correspondence to: A. Orphanou

(orphanoua@yahoo.gr)

\section{Introduction}

The local model LME (Doms and Schättler, 2002; Steppeler et al., 2003; Schulz, 2005) was developed by the German Weather Service (DWD). Its pre-operational phase started in January 2005 and in September 2005 it became operational. The boundary data for the LME are provided by the operational global model GME, for every hour. The horizontal resolution of the LME is $7 \mathrm{~km}\left(0.0625^{\circ}\right)$, while the atmosphere is represented by 40 layers in the vertical, ten of which resolving the boundary layer structure. The LME covers the whole European region, including the Mediterranean, Black, North and Baltic Seas. For the purpose of this study, a subarea was chosen, enclosed by meridians $20^{\circ} \mathrm{E}$ and $37^{\circ} \mathrm{E}$ and latitude circles $30^{\circ} \mathrm{N}$ and $40^{\circ} \mathrm{N}$.

\section{Data and methodology}

For the calculations, the forecast precipitation accumulations of the 00:00 UTC model runs for a 3-day forecast model output $(t+30, t+54$ and $t+78)$ were contrasted to the observed ones, during the eleven-month study period, namely, from 1 February to 31 December 2005. The forecast values used for the verification represent the average precipitation accumulations at selected grid boxes surrounding the stations.

The observations were made by three Automatic Weather Observing Systems located at the Airports of Larnaca $\left(33.37^{\circ} \mathrm{E}, 34.52^{\circ} \mathrm{N}\right)$ and Paphos $\left(32.49^{\circ} \mathrm{E}, 34.72^{\circ} \mathrm{N}\right)$ and at Athalassa station $\left(33.4^{\circ} \mathrm{E}, 35.1^{\circ} \mathrm{N}\right)$. The actual values used for the comparison represent the mean daily accumulated precipitation measured at Larnaka, Paphos and Athalassa and at 6,6 and 8 rain gauges within a radius of about $30 \mathrm{~km}$ around these locations, respectively. The grid boxes used for the verification, as well as the position of the rain gauges are shown separately for each station in Fig. 1. The closest available rain gauges within the selected grid box area

Published by Copernicus GmbH on behalf of the European Geosciences Union. 

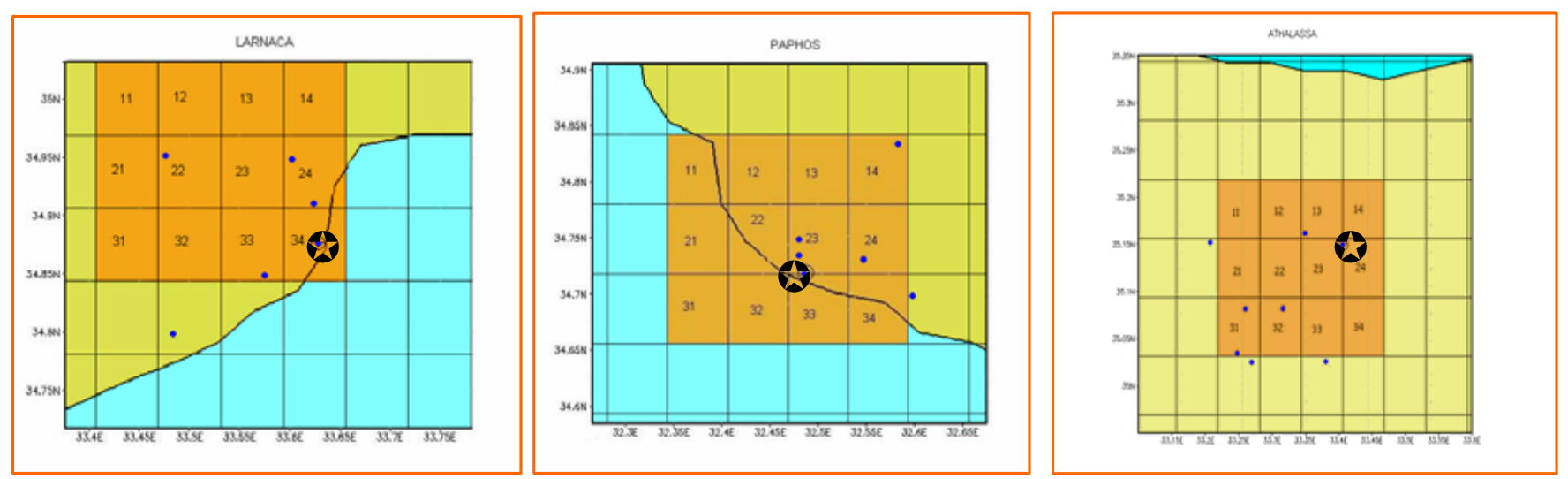

Fig. 1. The locations of Larnaka, Paphos and Athalassa stations (marked with star), their surrounding rain gauges (marked with blue dots) and the grid boxes used for the verification (orange boxes).

were chosen, while some others in the vicinity were also taken into account to extract the area average used in the verification. The "probability of detection" (POD), defined as the percentage of the number of cases where a precipitation event was observed and forecast by the model, to the number of cases where a precipitation event was observed, was calculated. The second calculated parameter is the "false alarm rate" (FAR), defined as the percentage of the number of cases where a precipitation event was forecast by the model but not observed, to the number of cases where a precipitation event was forecast. From the selected cases of precipitation events, the average forecast precipitation amounts in the area around the three stations were compared to the measured ones. The simple arithmetic mean was calculated for both the grid boxes and the rain gauges. For uniformity, 12 grid boxes had to be used for the verification. Since Paphos station is at almost sea level, the grid boxes were chosen so that the nearby mountainous region was excluded.

By using data from 150 rain gauges covering the island, maps of monthly precipitation totals were constructed. The distribution of these rain gauges and the location of the three stations are shown in Fig. 2.

\section{Verification of precipitation}

The evaluation of the skill of the LME model to forecast precipitation was carried out in two ways. The first is based on an in situ quantitative comparison of predicted and measured precipitation at the three stations and their surrounding areas and the second is based on a qualitative comparison of the spatial distribution of forecast and observed precipitation over the island of Cyprus.

For the in situ comparison, the calculations were done for the 11-month period, but also for the six months of the cyclone season, namely, February, March, April, October, November and December. It is within these months that the area of Cyprus is quite frequently affected by cyclonic systems (Meteorological Office, 1962; Reiter, 1975; Flocas et al., 2001; Michaelides et al., 2004; Nicolaides et al., 2004) that influence the amount of precipitation and its spatial distribution.

\subsection{In situ comparison}

The Probability Of Detection (POD) and False Alarm Rate (FAR) were calculated by comparing the averaged actual amounts of precipitation at each station with the accumulated forecast values corresponding to lead times D1, D2 and D3 $(t+30, t+54$ and $t+78$, respectively) of a model run. The calculations refer to the 11-month period and the two groups of months of the cyclone season.

The results in Tables 1, 2 and 3 suggest that Athalassa, which is located inland, has the lowest POD in almost all periods and lead times, compared to the other two coastal stations, namely, Larnaka and Paphos Airports; only at D2 during the two sub-groups of months POD is higher at Athalassa than at Larnaka. The percentages vary between $47-55 \%$ for D1, 53-57\% for D2 and 50-54\% for D3. It is worth pointing out that, in most cases, the POD at Athalassa is higher when the lead time of the model is increased (D2, D3), than when it is closer to the initial time of the model run (D1), mainly during the first group of months. The FAR at Athalassa remains much the same at all lead times, but increases with lead time at the other two stations.

Similar results with Athalassa were found for Larnaka, but more promising, since both POD and FAR have more trustworthy values. The POD varies between $63-68 \%$ for D1, $44-50 \%$ for D2 and $67-73 \%$ for D3. In addition, it is worth noting that the model performs much better in detecting precipitation for D3 than for D2 at Larnaka.

Overall, the best performance of the model in all periods and all days was for Paphos, the western coastal station, in which the highest POD was measured. It varies between 


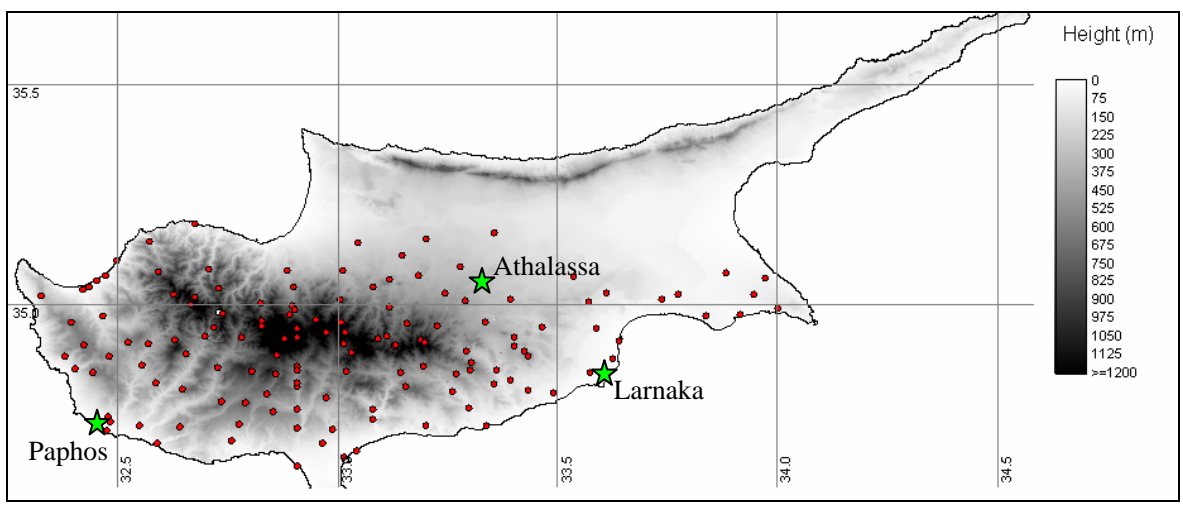

Fig. 2. Morphological map of Cyprus showing the network of rain gauges (indicated as red circles) and the position of the three synoptic stations referred to in the text (indicated as green stars).

Table 1. POD and FAR of precipitation forecast for Athalassa, Larnaka and Paphos one (D1), two (D2) and three (D3) days ahead, for the 11-month study period.

\begin{tabular}{ccccccc}
\hline Stations & \multicolumn{5}{c}{ Days } \\
& \multicolumn{2}{c}{ D1 } & \multicolumn{2}{c}{ D2 } & \multicolumn{2}{c}{ D3 } \\
\hline & POD & FAR & POD & FAR & POD & FAR \\
\hline Athalassa & 54.9 & 34.9 & 57.1 & 34.9 & 54.2 & 35.0 \\
Larnaka & 68.1 & 27.3 & 48.9 & 31.3 & 68.9 & 40.4 \\
Paphos & 73.3 & 31.3 & 68.2 & 34.8 & 72.1 & 35.4 \\
\hline
\end{tabular}

Table 2. POD and FAR of precipitation forecast for Athalassa, Larnaka and Paphos one (D1), two (D2) and three (D3) days ahead, for the first group of months, February, March and April.

\begin{tabular}{ccccccc}
\hline Stations & \multicolumn{5}{c}{ Days } \\
& \multicolumn{2}{c}{ D1 } & \multicolumn{2}{c}{ D2 } & \multicolumn{2}{c}{ D3 } \\
\hline & POD & FAR & POD & FAR & POD & FAR \\
\hline Athalassa & 47.6 & 41.2 & 55.0 & 47.6 & 52.6 & 44.4 \\
Larnaka & 63.2 & 29.4 & 50.0 & 43.8 & 66.7 & 52.0 \\
Paphos & 72.7 & 36.0 & 71.4 & 34.8 & 76.2 & 38.5 \\
\hline
\end{tabular}

$72-87 \%$ for D1, $68-73 \%$ for $\mathrm{D} 2$ and $71-76 \%$ for $\mathrm{D} 3$. The only exception is for D3 during the second group of months, where the POD at Larnaka was slightly higher. Regarding FAR, the results are similar to the other two stations: it increases with increasing lead time, in most of the cases.

Finally, it has been found that during the autumn and winter months (i.e. October, November and December), the model's skill was much more satisfactory compared to the rest of the study period, especially at Paphos, where there is a 14 percentage points higher POD on D1, than during the
Table 3. POD and FAR of precipitation forecast for Athalassa, Larnaka and Paphos one (D1), two (D2) and three (D3) days ahead, for the second group of months, October, November and December.

\begin{tabular}{ccccccc}
\hline Stations & \multicolumn{5}{c}{$\begin{array}{c}\text { Days } \\
\text { D2 }\end{array}$} \\
& \multicolumn{2}{c}{ D1 } & \multicolumn{2}{c}{ D3 } \\
\hline & POD & FAR & POD & FAR & POD & FAR \\
\hline Athalassa & 52.9 & 18.2 & 52.9 & 10.0 & 50.0 & 27.3 \\
Larnaka & 62.5 & 16.7 & 43.8 & 12.5 & 73.3 & 21.4 \\
Paphos & 86.7 & 18.8 & 73.3 & 26.7 & 71.4 & 28.6 \\
\hline
\end{tabular}

first group of months (i.e. February, March and April). At Athalassa, the POD is of similar order of magnitude, but the FAR is notably reduced.

During the in situ comparison, the cases of forecast precipitation events were selected and the average forecast precipitation amounts in the area around the three stations were compared with the measured ones. Due to space limitations the results shown in Fig. 3 refer to the first forecast day for each station during the two groups of months of the cyclone season.

The model tends to underestimate the amount of precipitation at Athalassa. In many cases though, the difference is close to zero, while the majority of the events where the model overestimated the accumulated values, were the ones when no precipitation was recorded by the rain gauges. A better fitting of the LME is spotted during the first 3-month period (cases to the left of the green vertical line), compared to the second one (cases to the right of the green vertical line). Similar results were found for Larnaka.

A not so explicit picture was found for Paphos. For the majority of the forecast precipitation events, there was an overestimation of the accumulated values, especially during the first 3-month period, while during the second 3-month period both overestimations and underestimations were noted. The 

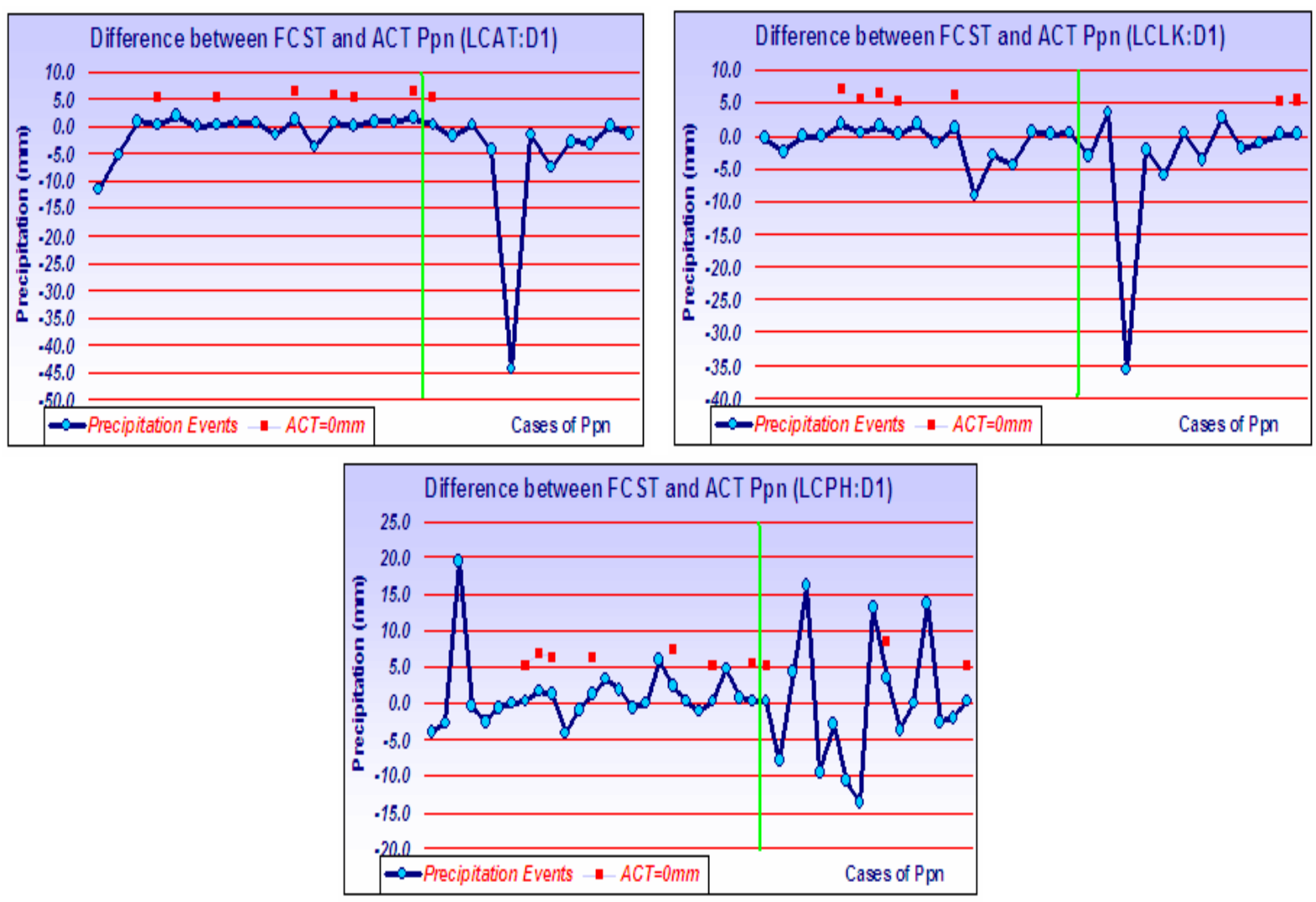

Fig. 3. Difference between the forecast and the actual mean precipitation amounts at Athalassa (top left), Larnaka (top right) and Paphos (bottom). The cases (days) to the left of the green vertical line refer to the first group of months, while the cases (days) to the right, to the second group. The cases of FAR are depicted and shown with red dots.

differences are much higher during the last period, reaching the amount of $15 \mathrm{~mm}$ of underestimation and overestimation.

It is worth mentioning that the striking notch where precipitation was significantly underestimated by the model at Athalassa and Larnaka stations during the second group of months, refers to the same weather situation that affected Cyprus on the 6 November 2005. In that case, precipitation was also underestimated at Paphos, but the underestimation was limited to $9.5 \mathrm{~mm}$.

\subsection{Spatial distribution of monthly precipitation forecasts}

An attempt was made to evaluate the model's skill in predicting the spatial distribution of precipitation. Precipitation forecasts from the 00:00 UTC model runs, from $t+06$ to $t+30$ were accumulated, in order to calculate the forecast monthly precipitation distributions, which were subsequently compared to the observed distribution of monthly precipitation revealed by 150 rain gauges operating on the island. Figure 4 shows the spatial distribution of forecast and observed precipitation for the six months of the cyclone season, February, March, April, October, November and December. A qualitative comparison of forecast and actual precipitation distributions lead to the following results:
1. The model is able to capture the basic characteristics of the seasonal variations of precipitation over Cyprus, but it underestimates the amount of the monthly precipitation in the spring season and strongly underestimates it during autumn and winter months.

2. The forecast maximum precipitation areas were located to the west part of the island, i.e. Paphos district and to the windward side of Troodos mountains (the central massif in Fig. 2).

3. The positions of the forecast maximum precipitation areas are displaced to the west and southwest of the positions of the observed maximum precipitation areas.

4. In the areas of maximum observed precipitation, the model forecasts very low values (for example, in February in areas with observed maximum values equal to $140 \mathrm{~mm}$ the model forecasts $20-30 \mathrm{~mm}$. 

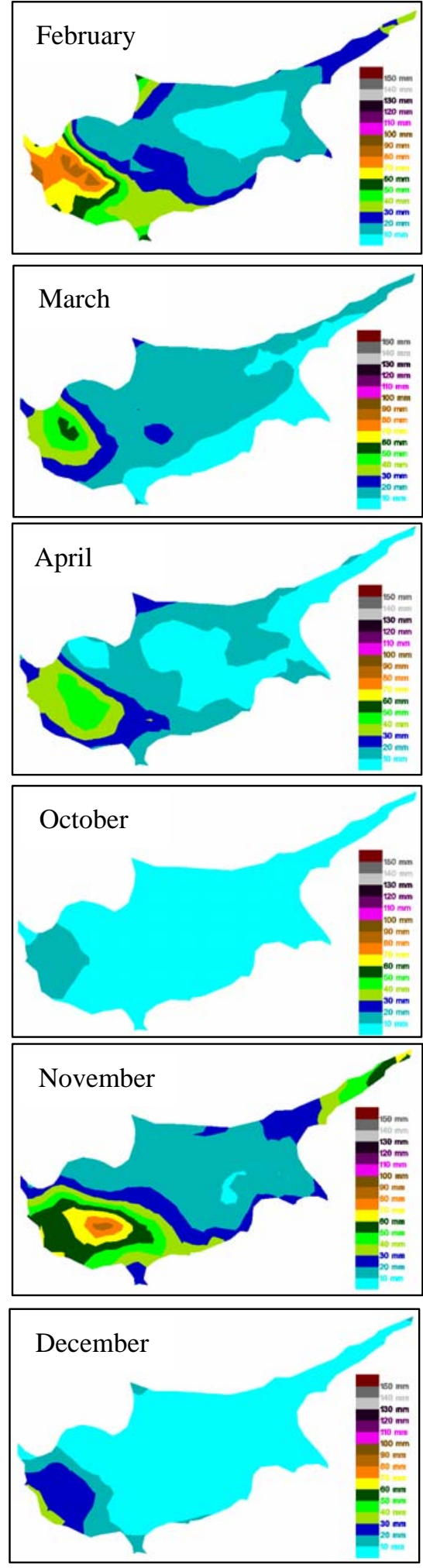

LME
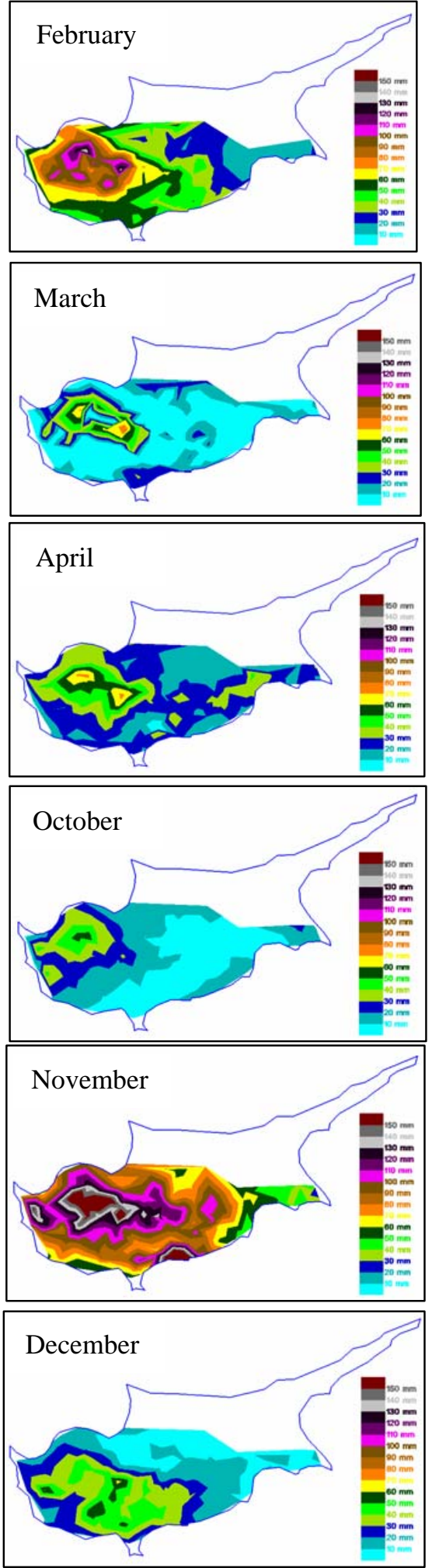

OBSERVED

Fig. 4. Verification of precipitation for the six months of the cyclone season. 


\section{Concluding remarks and future work}

In this study, a set of results has been presented regarding the verification of precipitation forecasts by the LME over Cyprus. This is the first effort made for the local model LME in this area and it has already contributed and will further contribute to the development of the model.

The in situ verification of precipitation showed that the model detects precipitation events better at the coastal stations, Larnaka and Paphos, rather than at Athalassa, the inland station. The amount of precipitation is mainly underestimated at Athalassa and Larnaka and overestimated at Paphos. During the 3-month period of October, November and December, the LME gives more trustworthy forecasts compared to the rest of the study period.

From the spatial distribution of the studied parameter, it can be considered that the model captures the basic characteristics of the seasonal variations of precipitation over Cyprus, but underestimates the amount of the monthly precipitation. The forecast maximum precipitation areas were located to the west part of the island, with the positions of the forecast maximum precipitation areas being displaced to the west and southwest of the positions of the observed maximum precipitation areas. In the areas of maximum observed precipitation, the model forecasts very low values.

It is obvious that the verification presented here is still not rigid and more work is needed in this direction. In the near future the following goals have been set:

- It is planned to increase the number of stations used in the verification, extending the verification over the mountainous area.

- The study period will extent for at least one more year, so that more representative results can be derived.

- Comparison of the LME with the global model of the DWD is planned. By contrasting the two models, a comparative evaluation of the performance of the local model LME will be made over the area of Cyprus.
Acknowledgements. Part of this work has been carried out within the framework of project Riskmed, partly funded by the European Regional Development Fund under its Programme Archimed, Interreg III, Strand B.

Edited by: S. C. Michaelides and E. Amitai

Reviewed by: anonymous referees

\section{References}

Doms, G. and Schättler, U.: A description of the nonhydrostatic regional model LM. Part I: Dynamics and Numerics, Deutscher Wetterdienst, Offenbach, 134 pp., available at: www. cosmo-model.org, 2002.

Flocas, H. A., Maheras, P., Karacostas, T. S., Patrikas, I., and Anagnostopoulou, C.: A 40-year Climatological study of relative vorticity distribution over the Mediterranean, Int. J. Climatol., 21, 1759-1778, 2001.

Meteorological Office: Weather in the Mediterranean, Vol. I, 2nd edition, HMSO, London, 1962.

Michaelides, S. C., Nicolaides, K., and Karacostas, T.: Statistical characteristics of the cold season depressions over the area of Cyprus, Meteorologický Èasopis, 7, 61-66, 2004.

Nicolaides, K., Michaelides, S. C., and Karacostas, T.: Spatial distribution of some dynamic parameters during the evolution of selected depressions over the area of Cyprus, Int. J. Climatol., 24, 1829-1844, 2004.

Reiter, E. R.: Handbook for forecasters in the Mediterranean, Naval Postgraduate School, Monterey, California, USA, 1975.

Schulz, J.-P.: Introducing the Lokal-Modell LME at the German Weather Service, COSMO Newsletter, 5, 158-159, available at: www.cosmo-model.org, 2005.

Steppeler, J., Doms, G., Schättler, U., Bitzer, H. W., Gassmann, A., Damrath, U., and Gregoric,G.: Meso-gamma scale forecasts using the nonhydrostatic model LM, Meteorol. Atm. Phys., 82, 75-96, 2003. 